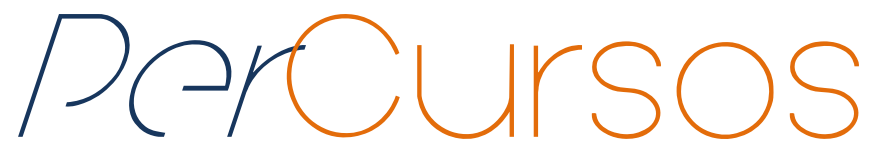

\title{
Práticas, recursos e linguagens no ensino de Geografia
}

\begin{abstract}
Resumo
No presente artigo buscamos refletir brevemente acerca das origens do ensino de Geografia, bem como de elementos como linguagens, recursos, procedimentos etc. os quais nos auxiliam a compreender como os currículos são tornados realidade, nesse Espaço (e Lugar) que chamamos escola. Nesse sentido, sublinhamos que esses mesmos elementos não apresentam, na prática docente, a mesma autonomia que as nossas abordagens teóricas conseguem lhes imprimir, sendo que, para ilustrar nossa proposição, demonstramos um recurso (ou material) didático com suas implicações no ensino. Concluímos nossa digressão tratando da linguagem cartográfica e também a relacionando com os elementos da prática docente, momento no qual reforçamos a relação entre teorias e práticas pedagógicas.
\end{abstract}

Palavras-chave: Processo Ensino-Aprendizagem. Metodologias. Linguagens. Tecnologia.

\author{
Elias Coimbra Silva \\ Doutor em História pela \\ Universidade Federal de \\ Uberlândia - UFU. Doutorando \\ em Geografia pela Universidade \\ Federal de Uberlândia - UFU. \\ Servidor Público do Município de \\ Ribeirão Preto - SP. \\ Brasil \\ coimbraelias@hotmail.com
}

\section{Para citar este artigo:}

SILVA, Elias Coimbra. Práticas, recursos e linguagens no ensino de Geografia. Revista PerCursos,

Florianópolis, v. 18, n.37, p. 212 - 228, maio/ago. 2017.

\section{DOI: $10.5965 / 1984724618372017212$}

http://dx.doi.org/10.5965/1984724618372017212 


\title{
Practices, resources and languages in teaching of Geography
}

\begin{abstract}
In this article we seek to think briefly about the origins of teaching of Geography, as well as elements such as languages, resources, procedures, etc. which help us to understand how curricula became reality in this space (and place) that we call school. Thus, we emphasize that these same elements not present in the teaching practice the same autonomy that our theoretical approaches can impose them, since to illustrate our proposition, we demonstrate a didactic resource (or didactic material) along with their implications for teaching. We conclude our presentation analyzing cartographic language and also relating it to the elements of teaching practice; moment in which we emphasize the relationship between pedagogical theories and practices.
\end{abstract}

Keywords: Teaching/Learning Process. Methodology. Languages. Technology. 


\section{Introdução}

A História da Geografia não é simplesmente uma sucessão cronológica de fatos considerados mais ou menos significativos, mas um complexo roteiro que tange múltiplas outras histórias: das ciências, da Pedagogia, ou mesmo dessa ou daquela nação. Entre tais escalas, que compõem essa espécie de "viagem temporal”, a sincronia raramente ocorre, de modo que discrepâncias entre o desenvolvimento da Educação, por exemplo, e do Ensino de Geografia são patentes.

De fato, mesmo no interior do próprio Ensino de Geografia, existem discrepâncias, e não apenas fundamentadas na temporalidade, mas em toda sorte de fatores. Assim é que, no presente texto, nosso objetivo é analisar algumas práticas empregadas no Ensino de Geografia, as suas subsequentes metodologias, linguagens e recursos envolvidos, além das interseções existentes entre esses diversos elementos, pois, se as finalidades do Ensino de Geografia são pouco discutíveis, ou seja, a aprendizagem significativa dos conteúdos presentes no currículo (BRASIL. Ministério da Educação. Secretaria de Educação Básica, 2006, p. 44) os meios para se alcançar essas finalidades evocam acalorados debates.

Destacaremos, na sequência, o papel da Cartografia no trabalho docente, em razão de sua importância para a Geografia, assim como pelo fato de que, entre os descompassos temporais que podemos aqui apontar, o mais significativo é, provavelmente, aquele que afasta o professor de geografia no ensino básico, das atuais tecnologias. Claro que isso não implica dizer simplesmente que os professores estão desatualizados, pois, as estruturas que amparam o seu trabalho distam ainda mais do “tempo das tecnologias”. Algo que as palavras de Mozart Ramos (BRASIL, 2016) ilustram com bastante eloquência: "temos uma Escola do século XIX, um Professor do século XX e um Aluno do século XXI". 


\section{O ensino de Geografia: das linguagens aos recursos didáticos}

A Geografia, se a entendemos como uma "visão sintética das múltiplas relações entre grupos humanos e seus marcos naturais" ${ }^{1}$, deve buscar as suas origens no pouco distante século XIX. Outrora, questões que tangenciavam os objetivos daquilo que veio a se configurar enquanto geografia eram já colocadas:

Por exemplo, o historiador grego Heródoto investigou os processos envolvidos na criação do delta do Rio Nilo. Frequentemente, essas especulações prístinas mostraram-se falsas, mas, ainda assim, foi importante levantar questões acerca de processos: qual é a sequência de eventos, tanto física quanto culturalmente, que explica uma paisagem? (PITZL, 2004, p. 87, trad. nossa) ${ }^{2}$

Mas, ainda não podíamos falar em pesquisa sistemática, "falseabilidade" (POPPER, 1972) ou quaisquer outros critérios de estrita cientificidade. Assim, a começar com Alexander Von Humboldt, menos um geógrafo do que um "naturalista", passando por Karl Ritter e chegando até Friedrich Ratzel, a moderna Geografia nasceu junto do “Segundo Reich" - como ficou conhecida a unificação, em 1871, de 27 territórios naquilo que conhecemos enfim por Alemanha.

No século XVIII, assistiu-se o advento do Ensino de Geografia num dos 27 territórios que compõem a hodierna Alemanha, sob a batuta de ninguém menos do que o

\footnotetext{
1 "Sin el reconocimiento y la aceptación de cierto determinismo, la geografía pierde a la vez su unidad y su originalidad; su unidad porque, fragmentada en una geografía física y una geografía humana, se identificará rápidamente con las ciencias humanas por una parte y con las ciencias naturales por otra; su originalidad que reside justamente en esta visión sintética de las relaciones múltiples que mantienen desde hace milenios los grupos humanos y sus marcos naturales." (PINCHEMEL, P. Géographie et déterminisme. Bulletin de la Société belge d'Etudes géographiques. Vol. 26, p. 211-225, 1957. Apud: CLAVAL, 1974, p. 61)

${ }^{2}$ For instance, the ancient Greek historian Herodotus speculated on the processes involved in the creation of the Nile River delta. In many cases, these early speculations proved to be false, but it was still important to ask process questions: what is the sequence of events, both physical and cultural, that explains a landscape? (PITZL, 2004, p. 87, grifo do autor)
} 
filósofo iluminista Immanuel Kant ${ }^{3}$. Contudo, não se tratava de Geografia Escolar. Esta última figuraria décadas depois, no século XIX, nos currículos escolares alemães (RIBEIRO, 2011, p. 822) com finalidades político-ideológicas evidentes.

No Brasil, a Geografia Acadêmica (aquela trabalhada nas universidades) surgiria apenas em 1934, com a criação da USP. Aliás, tendo sido o “vidalino" Pierre Deffontaines - seguido de Monbeig - o primeiro catedrático (AB'SABER, 1994). Por outro lado, a Geografia Escolar existia desde 1832, ano em que ela: "foi introduzida, como disciplina secundária [...] pela reforma do Plano de estudos da Companhia de Jesus, denominado de Ratio Ataque Institutio Studiorum Societatis Jesu" (SOUZA; PEZZATO, 2010, p. 79). Posteriormente, em 1837 e com a fundação do Colégio Pedro II, no Rio de Janeiro, a geografia marcaria presença na grade curricular: agora como disciplina autônoma.

É útil, aliás, ressaltarmos que a distância temporal entre as duas geografias não se traduz em profundas diferenças. Posto que, cópia dos modelos franceses, a Geografia Escolar brasileira primava pelo descritivismo, pelo estudo mnemônico (SOUZA; PEZZATO, 2010, p. 80) e pelo enfoque sobre a Paisagem - essa "unidade do visível" (BRASIL. Ministério da Educação. Secretária de Educação Média e Tecnológica, 2002, p. 56). Assim foi que por décadas, sob a influência dessa Escola Francesa e da Pedagogia Tradicional, a geografia ensinada nas escolas não passava de um exercício repetitivo de memorização das nomenclaturas: Rio Reno, Montes Apalaches, Condado de Kent etc.

Apenas na segunda metade do século $X X$ as alterações que estavam se processando na Pedagogia - lembremos que o Escolanovismo data do final do século XIX - começam a influenciar o Ensino de Geografia. Já não era sem tempo, pois as profundas modificações sociais exigiam modificações também na educação. De qualquer forma, esse atraso é compreensível, na medida em que o "Manifesto dos Pioneiros da Educação

\footnotetext{
3 “Contudo, a Geografia de Kant era fruto de um conjunto de conhecimentos e informações resultantes de relatos de viagens e compêndios que sintetizam os aspectos fisiográficos de várias partes do planeta. É esse material que organiza, sistematiza e classifica produzindo algo que poderia ser chamado de taxonomia do mundo físico." (RIBEIRO, 2011, p. 821)
} 
Nova"4 - o elemento e fato que incluiria o Brasil entre os países com adeptos do Escolanovismo - é de 1932 (AZEVEDO, 2010).

Nesse ponto, cabe destacar que o século XX assistiu a um desenvolvimento tecnológico ímpar, mas que, de um modo geral, pouco impactou as metodologias de ensino no Brasil - país cujo PIB, por exemplo, cresceu mais de 100 vezes nesse mesmo século (IBGE; BRASIL. Ministério do Planejamento, Orçamento e Gestão, 2006) -, metodologias que se mantiveram praticamente com a linguagem falada e a linguagem escrita. De fato, apesar da centralidade da chamada linguagem verbal (no caso do português, também alfabética) os PCN são explícitos quanto ao papel da linguagem cartográfica para a Geografia e para a formação geral dos estudantes. Além disso, outras modalidades dessa "matriz" gráfica podem auxiliar no ensino de geografia, tal é o caso dos audiovisuais e da narrativa visual (os chamados "quadrinhos").

Linguagens verbais e linguagens gráficas, portanto, podem ser mobilizadas para tornar a "aprendizagem significativa" - ou, para utilizar a expressão consagrada: Meaningful Learning (AUSUBEL, 2000). Aqui, destacamos a Alfabetização Cartográfica, uma vez que o mapa é, tradicionalmente, parte do conhecimento geográfico. Com justiça, posto que o estudo do espaço não deve se distanciar de sua representação ${ }^{5}$ - sob pena de sofrer prejuízos.

Todavia, as possibilidades com a matriz gráfica extrapolam em muito os limites da Cartografia, principalmente considerando uma sociedade (como a contemporânea) na qual as imagens proliferam. Donato e Lima (2010), para ficarmos com um exemplo, relatam a utilização do software "Movie Maker”, da empresa Windows, para produção de vídeos em sala de aula.

Por outro lado, seja a revista em quadrinhos, seja o filme, os recursos dos quais o professor de Geografia dispõe existem em proporção direta às linguagens. Pois, embora essa divisão analítica justifique-se no âmbito teórico, na prática, em sala de aula, o

\footnotetext{
${ }^{4}$ Apesar da variedade de matizes (Materialismo Histórico, Determinismo etc.) o essencial do documento pode ser buscado na ideia de aproximar escola e ciências - lato sensu. O que, portanto, a afastava do "eruditismo" da Pedagogia herdada desde os jesuítas.

5 “[...] a compreensão do mapa por si mesma já traz uma mudança qualitativamente superior na capacidade do aluno pensar o espaço". (PISSINATI; ARCHELA, 2007, p. 172)
} 
professor mobiliza recurso, procedimento, linguagem e filosofia de ensino simultaneamente. A propósito, cabe indicarmos nesse ponto algumas definições, considerando a variedade dos termos.

Assim, entendemos por procedimento - ou aquilo que Freitas (2007, p. 14) denomina "técnica"- o elemento estritamente prático do ensino, enquanto que a metodologia - que Freitas denomina “método" (FREITAS, 2007) - representaria a práxis ${ }^{6}$, a qual, a propósito, subsume os procedimentos. Além disso, entendemos por recurso (ou materiais, equipamentos, dispositivos etc.) esses artefatos, tais como o DVD do filme, o próprio livro didático, o "modelo de permeabilidade” (do qual já falaremos) entre outras coisas através das quais os procedimentos de ensino são efetivados.

De volta à questão principal, temos que os recursos, as linguagens e a concepção pedagógica estão presentes na práxis docente - esteja o professor consciente ou não dessa circunstância ${ }^{7}$. Nesse sentido, ao selecionar um filme (o recurso) - e, obviamente, considerando os objetivos - qualquer professor opta pela utilização de uma linguagem (nesse caso, complexa). Paralelamente, adotará uma certa filosofia - as chamadas "abordagens do processo ensino/aprendizagem" (MIZUKAMI, 1986) - que orienta as suas ações enquanto docente. Assim, o Comportamentalismo (por exemplo) implica numa certa visão de mundo mecanicista segundo a qual as pessoas são permanentemente “reprogramáveis" além de egoisticamente motivadas. Pois bem. Um professor pautado pelo Comportamentalismo, lançando mão de um filme qualquer (o recurso), esperaria que a mera audiência do vídeo, conquanto esse estivesse rigorosamente vinculado aos objetivos de uma determinada aula, fosse o suficiente para que o "aprendizado" se efetivasse.

Ora. Não à toa optamos pelo termo "aprendizado" (aquém do sentido processual do outro termo: "aprendizagem”), posto que nem o vídeo em si mesmo é capaz de realizar o trabalho docente - ao contrário do que pensam os propaladores do "Telecurso

\footnotetext{
${ }^{6} \mathrm{O}$ agir orientado (epistemológica ética e esteticamente) do professor, o qual "assume o papel de mediador entre a cultura elaborada, acumulada e em processo de acumulação pela humanidade, e o educando." (LUCKESI, 1994, p. 115)

${ }^{7}$ No mesmo sentido em que Luckesi (1994) nos fala em "senso comum pedagógico". Pois, frequentemente, em função da sobrecarga de trabalho, os professores reproduzem ações e discursos dos quais não conhecem as origens nem a função.
} 
2000" - nem o conhecimento ocorre por essa espécie de "transferência" objetiva (ou transmissão) de conteúdos. Aliás, falar em transmissão de conhecimento - e muitos professores incorrem nesse equívoco -, automaticamente implica em assumir um ponto de vista filosófico: nesse caso, empiricista.

Concluindo este subtítulo do artigo, tratemos da utilização de um recurso (ou material) específico. Para além das já consagradas maquetes, outros modelos têm sido utilizados em sala de aula, posto que no Estágio Operatório Concreto (dos 7 aos 11 anos) a aprendizagem não se separou completamente das experiências sensórias ${ }^{8}$ - o que deverá ocorrer a partir dos 11 anos de idade. Lembrando que a divisão nessas faixas etárias é uma referência, e não uma norma rígida (FURTADO; BOCK; TEIXEIRA, 1999), mesmo porque "ao que se sabe, ele [Piaget] nunca participou diretamente nem coordenou uma pesquisa com objetivos pedagógicos" (COLL, 1992, p. 172).

Assim, o exemplo que oferecemos deriva do conteúdo conceitual: o Aquífero Guarani, conteúdo esse que pode ser trabalhado, inicialmente, com a atividade de aprendizagem denominada por nós de “modelo de permeabilidade”. Para tal, recorta-se ao menos duas garrafas PET, colando-se no bico das garrafas tufos de algodão, os quais vão impedir que a amostras de areia e de argila, depositadas nos respectivos funis, sejam carregadas com a água, no " $5^{\circ}$ momento" que a "Figura-1" ilustra:

\footnotetext{
8 "Tanto as operações como as estruturas que se constroem até aproximadamente os onze anos, são de natureza concreta; permanecem ligadas indissoluvelmente à ação da criança sobre os objetos. Entre os 11 e os 15-16 anos, aproximadamente, as operações se desligam progressivamente do plano da manipulação concreta. Como resultado da experiência lógico matemática, o adolescente consegue agrupar representações de representações em estruturas equilibradas [...] e tem acesso a um raciocínio hipotético-dedutivo. Agora, poderá chegar a conclusões a partir de hipóteses, sem ter necessidade de observação e manipulação reais." (CAVICCHIA, 2010, p. 12)
} 


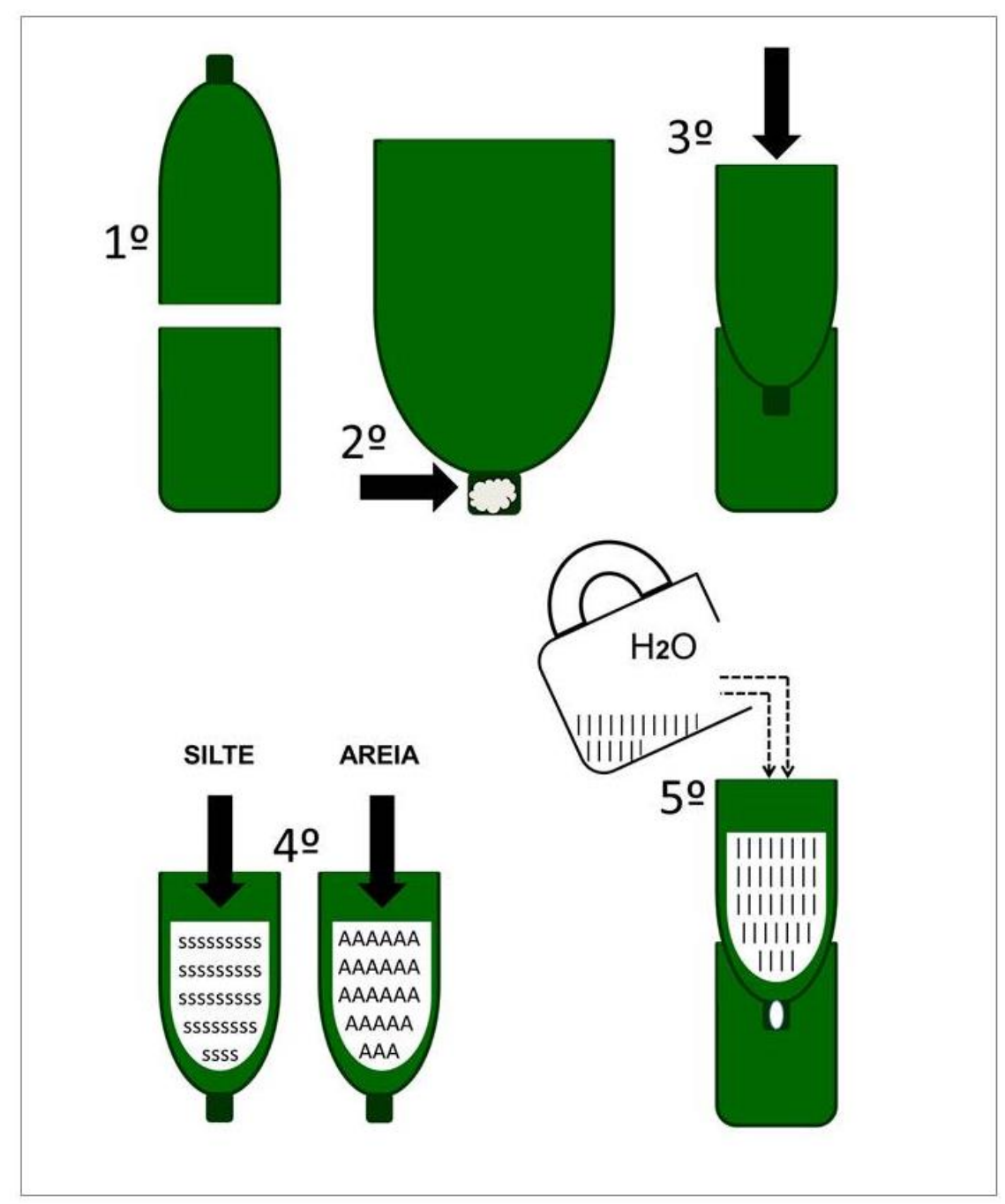

Figura 1 - Modelo didático de permeabilidade. Fonte: Autor.

A velocidade na qual a água atravessa as amostras, por óbvio, será diferente. Pode até mesmo ocorrer que a argila configure-se como uma barreira intransponível, e, assim, a percepção dessa propriedade dos solos possa auxiliar os alunos a pensarem sobre a capacidade que o arenito (rocha que compõe o famoso aquífero) apresenta, em "reservar" a água.

Lembremos que o estudo do Aquífero Guarani está amplamente apoiado pelos livros didáticos, uma vez que estes livros baseiam-se em publicações oficiais, sobretudo os PCN. Assim, um dos temas do EIXO-1 "A construção do espaço: os territórios e os lugares (o tempo da sociedade e o tempo da natureza)" do PCN (BRASIL. Ministério da Educação. Secretaria de Educação Fundamental, 1998) do Fundamental, oferece a ligação 
necessária entre o conteúdo (conceitual) em questão, ou seja, o Aquífero Guarani, e todo o material de apoio disponível. Com objetivos (por exemplo), de "levar o aluno a compreender como a sociedade se apropria da natureza" e entender que "os ritmos, duração e regularidades dos fenômenos naturais são definidos por leis que independem do trabalho humano, enquanto os da sociedade, pela intencionalidade das ações sociais no processo cuja temporalidade é chamada de tempo histórico" (BRASIL. Ministério da Educação. Secretaria de Educação Fundamental, 1998, p. 57).

Além disso, é útil ressaltar que, muito embora as múltiplas possibilidades - pois, sequer esmiuçamos a questão dos audiovisuais -, as linguagens verbais não são exploradas de todas as formas possíveis. Talvez, nesse caso, a fala mostre-se fortemente subestimada, pois os professores de Geografia (via de regra) não desenvolvem, durante seus anos de universidade, a mesma prática com as fontes orais observada entre os sociólogos, os antropólogos e os historiadores.

Nesse sentido, uma proposta de trabalho viável seria o estudo da dimensão temporal do Espaço - esse "acúmulo desigual de tempos" - a partir de entrevistas. Estudo esse que poderia ser realizado com pessoas mais velhas (os próprios parentes dos alunos, por exemplo). Lugares que não existem mais, paisagens que a modernização da cidade alterou etc. são todos elementos que podem ser reconstituídos a partir das memórias dos idosos. A propósito, nos chamados Atlas Escolares Municipais, as fontes orais de informação têm sido utilizadas, até mesmo como alternativa às fontes oficiais, "nuançando" assim a realidade?.

\section{Sobre o uso didático da cartografia}

Anteriormente, destacamos o impacto da tecnologia no século XX - do qual somos quase todos filhos - e a "metamorfose do espaço" brasileiro daí decorrente, de modo que é generalizada a consciência de que vivemos num período histórico muito diferente

\footnotetext{
${ }^{9}$ Por exemplo, no Atlas Municipal de Ribeirão Preto (LASTÓRIA, 2008), produzido pelo curso de Arquitetura e Urbanismo da USP, no tópico "Enchentes", após definições técnicas do que esse incidente significa, encontramos um box com um "relato de moradora da Vila Virgínia", relato no qual uma mulher anônima propõe o sentido que, para ela, a enchente possui.
} 
daquele no qual os pais da Geografia Moderna viveram: o século XIX. Assim, há quem afirme que experimentamos uma aceleração do tempo (CASTELLS, 2001, p. 554) e, no polo contrário, há quem concorde com Francis Fukuyama: que fomos tão longe que a "história acabou"10.

Em todo caso, o que caracteriza essa nossa "época veloz" é a presença generalizada de equipamentos (hardwares) - e, por conseguinte, de técnicas para utilizáIos, constantemente mais sofisticadas (JAMIL; NEVES, 2000). Equipamentos esses cujas finalidades diferem bastante: militar, administração, entretenimento e que, nesse sentido, são mais compulsórios do que gostaríamos que fossem. Na educação, sobre a qual depositamos nosso foco, não é diferente. Busquemos, então, entender essas tecnologias que afetam o ensino da geografia, assim como as metodologias a elas associadas.

De fato, autores das mais diversas procedências têm destacado a centralidade do Espaço para o entendimento dos fenômenos contemporâneos. O francês Foucault, por exemplo, produziu uma filosofia revolucionária escolhendo como um dos seus temas os “espaços disciplinares” (FOUCAULT, 2004). Assim, o Espaço ocupa hoje, entre as ciências humanas, uma posição semelhante àquela que, ainda no séc. XIX, o Tempo ocupava11 (quando as ideias de Progresso, Evolução etc. geravam infindáveis debates).

Mais do que uma questão apenas acadêmica, o Espaço tornou-se uma visão de mundo, uma "representação coletiva""12 necessária para que as pessoas, dentro ou fora da universidade, possam compreender o que está acontecendo. O próprio fato de que um dos equipamentos que mais tenha se difundido, ou seja, o GPS, utilizar o georreferenciamento, demonstra a popularidade desse tema (a espacialidade); ao

\footnotetext{
${ }^{10} \mathrm{O}$ think-tanker Fukuyama teria afirmado, em linhas gerais, que a Democracia Política, alicerçada no Liberalismo, é o ponto máximo de uma escala evolutiva da espécie humana. Tal afirmação foi publicada no jornal The National Interest, num artigo cuja repercussão foi muito maior do que a sua importância; seu título era: "O fim da história e o último homem", 1992.

11 "A obsessão do século XIX com o tempo e a história, como denominaria Foucault, continuou a enquadrar o pensamento crítico moderno. O primeiro capítulo começa e termina com a observação sintetizadora de Foucault: 'O espaço foi tratado como morto, o fixo, o não-dialético, o imóvel. O tempo, ao contrário, foi a riqueza, a fecundidade, a vida e a dialética."' (SOJA, 1993, p. 11)

12 "A representação é conceito ambíguo, [...] não é uma cópia do real, sua imagem perfeita, espécie de reflexo, mas uma construção feita a partir dele." (PESAVENTO, 2008, p. 40)
} 
mesmo tempo em que comprova a associação entre a tecnologia (outra questão em voga) e essa onda "espacializante" da sociedade contemporânea.

A escola, como parte dessa mesma sociedade, não se exime do debate e, nesse ponto, o papel do professor de geografia precisa ser posto em relevo, assim como a sua singularidade. Mas, em que sentido o trabalho desse professor é relevante e singular? perguntaríamos. Quer nos parecer que, em primeiro lugar, a presença da Linguagem Cartográfica - destacada nos PCN do Ensino Fundamental ${ }^{13}$ - nos indica uma resposta.

Evidentemente, a linguagem verbal é a base do ensino de geografia, como também da maioria das outras disciplinas. Porém, a importância da chamada alfabetização cartográfica na formação do leitor crítico e mapeador consciente - "O aluno deixou de ser visto como um mapeador mecânico para ser um mapeador consciente, de um leitor passivo para um leitor crítico dos mapas." (BRASIL. Ministério da Educação. Secretaria de Educação Fundamental, 1998, p. 77) - num mundo onde as espacialidades e as imagens proliferam, nos parece inegável.

Conforme a Professora Maria Simielli (2007), os elementos da alfabetização cartográfica são: visão oblíqua e vertical; imagem tridimensional e bidimensional; alfabeto cartográfico (ponto, linha e área); proporção e escala; lateralidade; referência e orientação. Além disso, a autora explica que tais elementos estarão presentes ao longo de todo o ensino básico, posto que o aluno terá sempre a necessidade de reforçar os conhecimentos adquiridos.

Uma segunda questão e que não se distancia da primeira (sobre a cartografia), no que tange à relevância do ensino de Geografia, refere-se às metodologias. Lembremos que, parágrafos antes, assumimos o pressuposto segundo o qual filosofias de ensino, linguagens, procedimentos e recursos se sobrepõem num todo sistêmico, no momento em que são mobilizados pelo docente, em sala de aula. De modo que podemos (já) partir da

\footnotetext{
13 “A cartografia torna-se recurso fundamental para o ensino e a pesquisa. Ela possibilita ter em mãos representações dos diferentes recortes desse espaço e na escala que interessa para o ensino e pesquisa. Para a Geografia, além das informações e análises que se podem obter por meio dos textos em que se usa a linguagem verbal, escrita ou oral, torna-se necessário, também, que essas informações se apresentem espacializadas com localizações e extensões precisas e que possam ser feitas por meio da linguagem gráfica/cartográfica." (BRASIL. Ministério da Educação. Secretaria de Educação Fundamental, 1998, p. 76)
} 
linguagem cartográfica - tipicamente associada à Geografia - para analisarmos essa segunda questão.

Podemos assim adotar a teoria conhecida como Epistemologia Genética de Piaget, tendo em mente a preocupação de Furtado, Bock e Teixeira (1999), já destacada aqui, para propor (abaixo) uma tipologia de cunho meramente ilustrativo, na qual os níveis de aprendizagem relacionados a dois ${ }^{14}$ dos chamados estágios do desenvolvimento cognitivo estão associados aos demais elementos constitutivos da práxis docente. Teríamos, então, as situações seguintes:

- No Estágio das Operações Concretas, que se perfaz dos 7 aos 11 anos de idade, portanto, equivale (em tese) à trajetória entre $2^{\circ}$ e $6^{\circ}$ anos do ensino fundamental, o qual é caracterizado pelo pensamento lógico - porém apoiado em situações empíricas e não situações hipotéticas - é possível trabalhar qualquer um dos elementos da alfabetização cartográfica; além das habilidades de "Iocalização" e "análise" (termos propostos por: SIMIELLI, 2007). Quanto aos recursos e procedimentos, sugerimos que os mapas mentais, as maquetes e os croquis sejam privilegiados pelo professor, na medida em que a experiência próxima do aluno será valorizada. Chamamos a atenção, nesse sentido, para a operacionalização dos conceitos de Lugar e Paisagem.

- No Estágio das Operações Formais, iniciado a partir dos 11-12 anos de idade e que, portanto, equivale à trajetória entre $6^{\circ}$ ano do fundamental e $3^{\circ}$ do ensino médio, estágio, por sua vez, caracterizado pelo pensamento lógico-abstrato, a partir do qual o raciocínio (plenamente desenvolvido) consegue lidar com símbolos e não apenas com exemplos concretos, as habilidades de "correlação" e “síntese" (SIMIELLI, 2007) podem ser acrescidas às de "localização" e "análise". Nesse ponto, os recursos podem diversificar-se e o Sensoriamento Remoto ou mesmo o SIG podem ser utilizados. Aliás, da mesma forma que o GPS, o SIG se

\footnotetext{
${ }^{14}$ Nos debruçamos apenas sobre os dois estágios que afetam, diretamente, o trabalho do professor do ensino básico, ou seja, o Operatório Concreto e o Operatório Formal. Segundo Luiz C. Abreu (2010, p. 363), o primeiro desses estágios está “[...] calcado na capacidade de coordenar ações bem ordenadas em 'sistemas de conjunto ou estruturas, suscetíveis de se fecharem' enquanto tais”. Ao passo que no segundo (desses dois estágios) as estruturas coordenadoras estão no plano simbólico, mais do que no plano das ações.
} 
tornou uma ferramenta muito popular (junto da difusão do uso da internet). Certamente todos conhecem o software "Google Earth", embora nem todo mundo saiba que se trata de um SIG.

Evidentemente e é útil destacarmos, a tecnologia não exclui a presença do Professor de Geografia na sala de aula, nem sua expertise para selecionar os procedimentos e técnicas mais idôneas para a aprendizagem significativa. Nesse ponto relativizando agora as tecnologias e seguindo na explicação sobre as metodologias creio que o trabalho de campo, quando possível, deve ser utilizado. Assim é que Pontuschka ressalta a necessidade de não se perder de vista o próprio Espaço enquanto recurso pedagógico: “O meio é uma geografia viva. A escola, o córrego próximo, a população de um bairro, o distrito industrial, [...] são elementos integrantes de um espaço, que podem ser pontos de partida para uma reflexão." (PONTUSCHKA, 2004, p. 260).

\section{Considerações finais}

Tentando concluir, entendemos que a Geografia (ciência e disciplina escolar) ocupa uma posição das mais pertinentes, dadas as condições do contexto histórico; condições brevemente aludidas no presente texto. Ao mesmo tempo, ela (Geografia) enfrenta a necessidade de se territorializar em meio às ciências humanas - lembremos que, com relação ao atual ensino médio, a História, a Sociologia e a Filosofia constituem as demais humanidades.

Finalmente, é também necessário um certo ativismo do próprio geógrafo para não perder seu espaço, no âmbito dos bacharéis, e, o que nos interessa aqui diretamente, não perder espaço no currículo escolar. Fato que ocorreu, há alguns anos, com a criação das licenciaturas curtas e com as disciplinas de cunho político-idealista como E.M.C. e O.S.P.B., que diminuíram as aulas de Geografia e de História, nas décadas de 1960-70:

As disciplinas de Educação Moral e Cívica e de Organização Social e Política do Brasil, quando inseridas no currículo, causaram a redução nas aulas semanais de História, Geografia e Estudos Sociais e nos seus respectivos conteúdos. A disciplina Organização 
Social e Política do Brasil surgiu em algumas séries do ginásio e do colegial a partir da publicação da Lei de 1961. (MIMESSE, 2007, p. 201-202)

Aliás, o debate em torno da autonomia dos professores em sala de aula é tão atual - escrevemos isso enquanto pensamos no movimento "Escola Sem Partido" - quanto o é a necessidade de disciplinas como a Geografia (ou a História).

\section{Referências}

ABREU Luiz Carlos et al. A epistemologia genética de Piaget e o construtivismo. Rev. Bras. Cresc. e Desenv. Hum., São Paulo, v. 20, n. 2, p. 361-366, 2010.

AB'SABER, Aziz. Pierre Monbeig: a herança intelectual de um geógrafo. Estudos Avançados, São Paulo, v. 8, n. 22, p. 221-232, set./dez. 1994.

AUSUBEL, David Paul.The acquisition and retention of knowledge: a cognitive view. Dordrecht, Boston-MA: Kluwer Academic Publishers, 2000.

AZEVEDO, Fernando et al.. Manifestos dos pioneiros da educação nova (1932) e dos educadores (1959). Recife: Fundação Joaquim Nabuco, Editora Massangana, 2010.

BRASIL tem escola do século XIX, afirma especialista em educação. G1-Globo, 8 nov. 2012. Disponível em: <http://g1.globo.com/globo-news/noticia/2012/11/brasil-tem-escola-doseculo-xix-afirma-especialista-em-educacao.html>. Acesso em: 20 set. 2016.

BRASIL. Ministério da Educação. Secretaria de Educação Básica. Orientações curriculares para o ensino médio: ciências humanas e suas tecnologias. Brasília, 2006, v. 3.

BRASIL. Ministério da Educação.Secretaria de Educação Fundamental. Parâmetros curriculares nacionais: geografia - terceiro e quarto ciclos do ensino fundamental. Brasília, 1998.

BRASIL. Ministério da Educação. Secretária de Educação Média e Tecnológica. PCN+ Ensino médio: orientações educacionais complementares aos Parâmetros Curriculares Nacionais. Brasília, 2002.

CASTELLS, Manuel. A sociedade em rede. Tradução de Roneide Venancio Majer. 8. ed. São Paulo: Paz e Terra, 2001.

CAVICCHIA, Durlei de Carvalho. O desenvolvimento da criança nos primeiros anos de vida. In: UNIVERSIDADE ESTADUAL PAULISTA; UNIVERSIDADE VIRTUAL DO ESTADO DE SÃO 
PAULO . Caderno de formação: formação de professores: educação infantil: princípios e fundamentos. São Paulo: Cultura Acadêmica: Universidade Estadual Paulista, Pró-Reitoria de Graduação, 2010. v.1. p.13-27.

CLAVAL, Paul. Evolución de la geografía humana. Barcelona: Oiko-Tau S.A, 1974.

COLL, César. As contribuições da psicologia para a educação: teoria genética e aprendizagem escolar. In LEITE, Luci Banks. (Org.). Piaget e a escola de Genebra. São Paulo: Editora Cortez,1992. p. 164-197.

DONATO, Larissa; LIMA, Maria das Graças de. O uso de tecnologias no ensino de geografia: os recursos audio-visuais. In: ENCONTRO NACIONAL DOS GEÓGRAFOS, XVI, Porto Alegre 2010. Anais... Porto Alegre: AGB, 2010, p. 1-6.

FOUCAULT, Michel. Vigiar e punir: nascimento da prisão. 29. ed. Tradução de Raquel Ramalhete. Petrópolis: Vozes, 2004.

FREITAS, Olga. Equipamentos e materiais didáticos. Brasília: Universidade de Brasília, 2007.

IBGE; BRASIL. Ministério do Planejamento, Orçamento e Gestão. Estatísticas do Século XX. Rio de Janeiro, 2006.

FURTADO, Odair; BOCK, Ana Mercês Bahia; TEIXEIRA, Maria de Lourdes Trassi. Psicologias: uma introdução ao estudo de psicologia. 13. ed. São Paulo: Saraiva, 1999.

JAMIL George Leal; NEVES Jorge Tadeu de Ramos. A era da informação: considerações sobre o desenvolvimento das tecnologias da informação. Perspect. cienc. inf., Belo Horizonte, v. 5, n. 1, p. 4 -53, jan./jun. 2000.

LASTÓRIA, Andréa Coelho (Org.). Atlas escolar histórico, geográfico e ambiental de Ribeirão Preto-SP: Grupo de Estudos da Localidade. Ribeirão Preto: Universidade de São Paulo, 2008.

LUCKESI, Cipriano Carlos Filosofia da educação. São Paulo: Cortez, 1994.

MIMESSE, Eliane. A implantação dos estudos sociais nas grades curriculares das escolas estaduais nos anos de 1970 e a formação acadêmica do professor. Educere et educare, Cascavel-PR, v.2, n.4, p. 193-204, jul./dez. 2007.

MIZUKAMI, Maria da Graça Nicoletti . Ensino: as abordagens do processo. São Paulo: EPU, 1986. 
PESAVENTO, Sandra Jatahy. História \& história cultural. 2. ed. Belo Horizonte: Autêntica, 2008.

PISSINATI, Mariza Cleonice; ARCHELA, Rosely Sampaio. Fundamentos da alfabetização cartográfica no ensino de geografia. Geografia. Londrina-PR, v. 16, n. 1, p. 169-195, jan./jun. 2007.

PITZL, Gerald Rudolph. Encyclopedia of human geography. Westport-CT; London: Greenwood Press, 2004.

PONTUSCHKA, Nídia Nacib. O conceito de estudo de meio transforma-se... em tempos diferentes, em escolas diferentes, com professores diferentes. In: VESENTINI, José W. 0 ensino de geografia no século XXI. Campinas: Papirus, 2004.

POPPER, Karl Raimund. a lógica da pesquisa científica. Tradução de Leonidas Hegenberg e Octanny Silveira da Mota. São Paulo: Cultrix, 1972.

RIBEIRO, Márcio Willyans. Origens da disciplina de geografia na Europa e seu desenvolvimento no Brasil. Rev. Diálogo Educ. Curitiba, v. 11, n. 34, p. 817-834, set./dez. 2011.

SILVA, Marcos; FONSECA, Selva Guimarães. Ensinar história no século XXI: em busca do tempo entendido. Campinas: Papirus, 2007.

SIMIELLI, Maria Elena Ramos. Cartografia no Ensino Fundamental e Médio. In: CARLOS, Ana Fani Alessandri (Orgs.). A geografia na sala de aula. São Paulo: Contexto, 2007.

SOJA, Edward W. Geografias pós-modernas: a reafirmação do espaço na teoria social. Tradução de Vera Ribeiro. Rio de Janeiro: Jorge Zahar, 1993.

SOUZA, Thiago Tavares de; PEZZATO, João Pedro. A geografia escolar no Brasil de 1546 até a década de 1960. In: GODOY, Paulo Roberto Teixeira. (Org.) História do pensamento geográfico e epistemologia em geografia. São Paulo: Cultura Acadêmica, 2010.

Recebido em: 22/09/2016 Aprovado em: 01/06/2017

Universidade do Estado de Santa Catarina - UDESC Centro de Ciências Humanas e da Educação - FAED

Revista PerCursos

Volume 18 - Número 37 - Ano 2017 revistapercursos@gmail.com 